\title{
Optimalisasi Teknik Riset Operasional Untuk Penghematan Biaya Transportasi Pengiriman Buah Kelapa Sawit Dengan Metode North West Corner ( Studi Kasus PT.Agro Muko)
}

\author{
Mustadin \\ Sekolah Tinggi Ilmu Manajemen dan Komputer Gici - Batam \\ City Walk Lt.3 Kepri Mall telp: 0778749006 \\ E-mail: mustadim92@gmail.com
}

\begin{abstract}
PT.Agro Muko is a plantation company that specifically manages the Palm. In the process of management of oil palm plantations starting up to mills, needed a transport process in the delivery of oil palm fruit. A large number of gardens and objectives Shipping Oil Palm cause not optimal transportation costs shipping costs Coconut Oil. North West Corner (NWC) is a method to optimize transportation costs by calculating the total costs, the cost of fares and service delivery. NWC implemented to deal with the cost of shipping oil palm fruit at Muko PT.Agro order to optimize the transportation cost savings. On the data at Muko PT.Agro Coconut Oil shipping costs can be optimized by $3.66 \%$ from the current shipping costs. So that transportation costs shipping costs Coconut Oil PT.Agro Muko has been optimal.
\end{abstract}

Keywords : Optimization of Delivery, Transportation Cost Savings, methods North West Corner (NWC).

\section{PENDAHULUAN}

Setiap perusahaan selalu mengharap kan keuntungan yang semaksimal mungkin agar siklus hidup perusahaan dapat tetap berjalan. Tujuan tersebut dapat tercapai apabila perusahaan dapat mempertahankan dan meningkatkan penjualannya. Khususnya pada PT.Agro Muko mengharapkan keuntungan yang semaksimal mungkin saat mendistribusikan produknya.

Ketika dihadapkan pada masalah tersebut, diperlukan perencanaan yang matang agar biaya transportasi yang dikeluarkan seefisien mungkin dan tidak menjadi hambatan yang dapat mengeluarkan biaya yang besar pada perusahaan.

Berdasarkan permasalahan tersebut, metode North West Corner $(N W C)$ dianggap efisien dalam menyelesaikan masalah mencari biaya transportasi seminimum mungkin.

\section{METODE PENELITIAN}

Metode North West Corner, Metode North West Corner diperkenalkan oleh Charnes dan Cooper, kemudian dikembangkan oleh Danzig. Caranya sebagai berikut : (Lim Sanny, 2011)

a. Mulai dari pojok barat laut pada tabel persoalan transportasi

b. Teruskan langkah ini, setapak demi setapak menjauh pojok barat laut sehingga akhimya harganya telah dicapai pada pojok tenggara dari tabel.

Operasi riset digambarkan sebagai suatu pendekatan ilmiah kepada pengambilan keputusan yang meliputi operasi dari sistem - sistem organisasi, dan berusaha menetapkan arah tindakan terbaik (optimum) dari sebuah masalah keputusan di bawah 
sumber daya yang terbatas (Claudia Nelwan, et al , 2013)

MetodenPenelitian merupakan rancangan kegiatan ilmiah dalam rangka pemecahan suatu permasalahan. Penjelasan ataupun jawaban terhadap sebuah permsalahan dapat bersifat abstrak dan umum sebagaimana halnya dalam penelitian dasar. Suatu penelitian biasanya selalu dimulai dengan suatu perencanaan yang seksama yang mengikuti serentetan petunjuk yang disusun secara logis dan sistematis sehingga hasilnya dapat mewakili kondisi yang sebenarnya dan dapat dipertanggung jawabkan. Kerangka penelitian yang jelas akan memberikan banyak kemudahan dalam memecahkan permasalahan yang diteliti, dan mempemudah dianalisa jika terdapat kekurangan dan kesalahan dalam penelitian.

Metodologi penelitian erat kaitannya dengan prosedur, alat, serta desain penelitian yang dipergunakan didalam melaksanakan penelitian. Tahapan proses dalam penelitian ini mengalir sesuai dengan alur yang logis. Tujuannya adalah memberikan petunjuk yang jelas, teratur dan sistematis. Susunan tahapan ini sangat mempengaruhi mutu dari hasil yang diperoleh nantinya. Tahapan dalam penelitian ini dapat dilihat pada gambar 3.1. Penyajian dalam bentuk diagram ini dimaksudkan agar dapat mudah dipahami.

\section{Kerangka Kerja (Framework)}

Dalam penelitiaan, dibutuhkan kerangka kerja yang mampu menggambarkan tahapan-tahapan yang harus dilaksanakan sehingga proses penelitian dapat berjalan dengan baik dan menghasilkan kesimpulan yang jelas. Pada penelitian ini akan menggunakan kerangka kerja yang nantinya akan dilaksanakan secara sistematis dimana tahapantahapan kerangka kerja dapat digambarkan pada gambar dibawah ini.

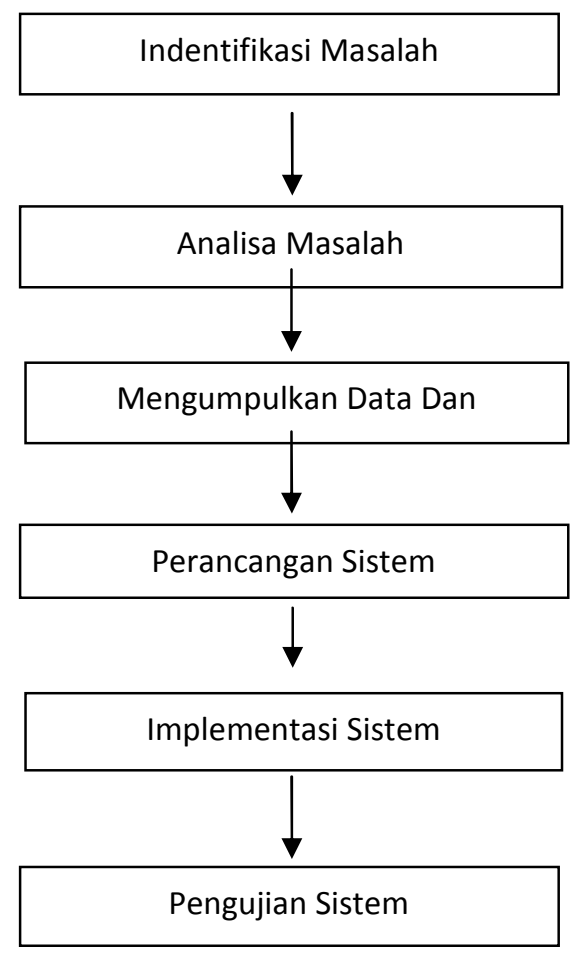

\section{Gambar 3.1 Kerangka Kerja (Framework)}

\section{Indentifikasi Masalah}

Mendefinisikan segala permasalahan yang ada, sehingga proses penenlitian dapat dimulai dengan memberikan penjelasan terhadap permasalahan yang akan diteliti, secara terstruktur ataupun secara sistematis untuk menyelesaikan permasalahan dan untuk mengambil suatu keputusan yang lebih baik. Pada penelitian ini ada beberapa permasalahan yang telah didefenisikan pada bab sebelumnya.

\section{Analisa Masalah}

Untuk mempermudah dalam melakukan analisis masalah maka perlu ditentukan batasan-batasan dari permasalahan yang akan diteliti. Setelah menentukan batasan 
permasalahan, penelitian juga membutuhkan metode yang dapat digunakan dalam menganalisa permasalahan. Metode yang dapat digunakan pada penelitian ini

\section{Mengumpulkan Data Dan Informasi}

Dalam proses pengumpulan data informasi perlu dilakukan observasi yaitu pengamatan secara langsung di tempat penelitian sehingga permasalahan yang ada dapat diketahui dengan jelas. Melakukan analisa terhadap data dan informasi yang tepat.

\section{Perancangan sistem}

Tahap perancangan sistem akan merumuskan dan mengidentifikasi kebutuhan- kebutuhan sistem yang akan di ranacang Rancangan yang jelas dan lengkap akan sangat berpengaruh dalam tahapan implementasi sistem. Berikut adalah tahapan dlam perancangan sistem yang penulis lakukan yaitu:

\section{A. Mempelajari Literatur}

Untuk mencapai tujuan yang akan ditentukan, maka perlu dipelajari beberapa literatur-literatur yang digunakan. Kemudian literaturliteratur yang dipelajari tersebut diseleksi untuk dapat ditentukan literatur mana yang akan digunakan dalam penelitian. Adapun literatur yang digunakan adalah :

\section{a. Jurnal}

Jurnal-jurnal yang dapat dijadikan sebagai referensi adalah jurnal yang berkaitan dengan Riset Operasioanal , Pengiriman buah kelapa sawit, metode North west Corner dan jurnal-jurnal lainnya yang berhubungan dengan judul penelitian.

\section{b. Buku}

Buku yang dapat dijadikan sebagai referensi juga merupakan berhubungan dengan penelitian yang dilakukan.

\section{Implementasi Sistem}

Implementasikan menggunakan bahasa pemrograman Microsoft visualbasic2008. Pengujian dilakukan untuk mengetahui hasil yang didapatkan pada tahap implementasi sistem yang dibuat sehingga dapat Mengoptimalisasi biaya transportasi pada pengiriman Buah kelapa Sawit di PT.Agro muko

6. Pengujian Sistem

Pengujian Sistem merupakan tahap akhir dari penelitian yang bertujuan untuk memberikan hasil akhir dari sistem yang dirancang, apakah sudah sesuai dengan yang dibutuhkan atau masih perlu pengembangan, serta dilengkapi dengan saran yang bertujuan untuk dapat mengembangkan sistem menjadi lebih baik sesuai dengan kebutuhan.

\section{HASIL DAN PEMBAHASAN}

Masalah transportasi adalah bagian dari operation research yang membahas tentang minimisasi biaya transportasi dari suatu tempat ke tempat lain. Permasalahan biaya transportasi merupakan suatu permasalahan dalam suatu perusahaan yang mengarah kepada seberapa keuntungan yang diperoleh perusahaan, semakin sedikit biaya yang dikeluarkan dalam transportasi barang akan semakin besar keuntungan yang didapat perusahaan tersebut. Sehingga diangkatlah kasus penyelesaian masalah transportasi menggunakan metode North West Corner pada PT. Agro Muko yang memiliki tiga Perkebunan di Wilayah Kabupaten Mukomuko yaitu Perkebunan TPE, SKGE, dan TRE.

Tibanya pengiriman buah kelapa Sawit PT.Agro Muko, tidak selalu dalam waktu yang bersamaan, sehingga perusahaan mengambil keputusan untuk mengirimkan Buah Kelapa Sawit ke Pabrik Muko Muko, Bunga Tanjung, Air Bikuk, Air Hitam, 
berdasarkan dari Pabrik mana yang menerima kiriman barang terlebih dahulu. Sehingga mengakibatkan borosnya biaya transportasi.

\subsection{Algoritma Sistem}

Adapun algoritma yang diterapkan dalam perancangan dan pembuatan sistem ini dengan menggunakan metode North West Corner adalah sebagai berikut :

\subsubsection{Algoritma North West Corner (NWC)}

1. Data dari PT.Agro Muko

Perusahaan PT.Agro Muko mempunyai Perkebunan di kabupaten Mukomuko yaitu TPE, SKGE, TRE. Dari ketiga lokasi ini akan melakukan pengiriman Buah kelapa sawit ke beberapa pabrik yaitu, Muko Muko, Bunga Tanjung, Air Bikuk, Air Hitam, di mana tarif yang akan digunakan adalah tarif pengangkutan dengan perincian sebagai berikut :

1. Dari gudang di TPE, akan dikeluarkan barang sebanyak 250 ton yang akan dikirim ke beberapa pabrik dengan perincian pada tabel 4.1.

2. Dari gudang di SKGE, akan dikeluarkan barang sebanyak 150 ton yang akan dikirim ke beberapa Pabrik dengan perincian pada tabel 4.2.

3. Dari gudang di TRE, akan dikeluarkan barang sebanyak 200 ton yang akan dikirim ke beberapa Pabrik dengan perincian pada tabel 4.3.

4. Kapasitas setiap pengantaran barang hanya mampu menampung 7,5 ton.

Perusahaan PT.Agro Muko mempunyai Perkebunan di kabupaten Mukomuko, Dari ketiga lokasi ini akan melakukan pengiriman Buah kelapa sawit ke beberapa pabrik yaitu, Muko Muko,
Bunga Tanjung, Air Bikuk dan Air Hitam, yaitu ;

1. Berikut ini adalah Tabel pengiriman Buah kelapa sawit dari TPE ( Talang Petai Estate) Yang akan dikirim ke beberapa pabrik, Di mana Masing-masing tempat mempunyai Tarif yang berbeda , yang ditetukan oleh PT. Agro Muko . Dengan perincian harga pengiriman Sebagai berikut ; Dari TPE ( Talang Petai Estate) ke ;

a. Pabrik Muko Muko: Rp 728.000

b. Pabrik Bunga Tanjung: Rp 680.000

c. Pabrik Air Bikuk : Rp 823.000

d. Pabrik Air Hitam : Rp 919.000

Dari data yang dikumpulkan pada PT.Agro Muko didapatkan list pengiriman dengan detial harga dan tarif yang telah ditentukan oleh PT.Agro Muko, selanjutnya dari data yang ada dilakukan implementasi algoritma NWC yang dimulai dari pembuatan tabel, artinya data yang berbentuk list informasi diubah menjadi bentuk tabel, seperti yang terihat pada tabel 4.1.

2. Membuat tabel North West Corner berdasarkan data yang telah dikumpulkan dari PT.Agro Muko

Tabel 4.1 Pengiriman Barang dari TPE

\begin{tabular}{|c|c|c|c|c|c|}
\hline $2: 2$ & Iujuse & $\begin{array}{c}\text { Janbl } \\
\text { Puyiciua } \\
\text { Tanịila: }\end{array}$ & 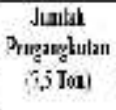 & $\begin{array}{c}\text { Turif } \\
\text { Fencirimes }\end{array}$ & Ital \\
\hline [स] & Birto lfito & 0 & 7 & $\because 200$ & ng sto\&m: \\
\hline$y^{2}$ & fusglojng & 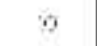 & $\therefore$ & $\sec 60$ & Es $j 0000)$ \\
\hline T.E & Gi:Bist & 30 & ¿] & 320.00 & $m+1639 x$ \\
\hline lut & if tian & 2 & 8 & Fina & By? \\
\hline & & & & & Myz:stx:os \\
\hline
\end{tabular}

Dari data yang didapatkan dari PT.Agro Muko bahwa selama proses pengangkutan dalam pengiriman hanya dapat dilakukan dengan beban maksimal sebesar 7,5 ton/sekali kirim. 
Jadi dapat dijelaskan dari data tabel 4.1 dari asal gudang TPE dengan tujuan pengiriman Muko Muko terdapat pengiriman sebanyak 11 (Sebelas) kali pengiriman. 10 pengiriman dengan kapasitas masingmasing 7,5 ton dan 1 pengiriman dengan kapasitas 5 ton.

2. Berikut ini adalah Tabel pengiriman Buah kelapa sawit dari SKGE ( Sei Kiang Estate) Yang akan dikirim ke beberapa pabrik, Di mana Masing - masing tempat mempunyai Tarif yang berbeda, yang ditetukan oleh PT. Agro Muko. Dari SKGE (Sei Kiang Estate) ke;

a. Pabrik Muko Muko, : Rp 490.000

b. Pabrik Bunga Tanjung, : Rp 442.000

c. Pabrik Air Bikuk, $\quad$ : $\quad$ Rp 585.000

d. Pabrik Air Hitam, $\quad$ : $\quad$ Rp 680.000

Tabel 4.2 Pengiriman Barang dari

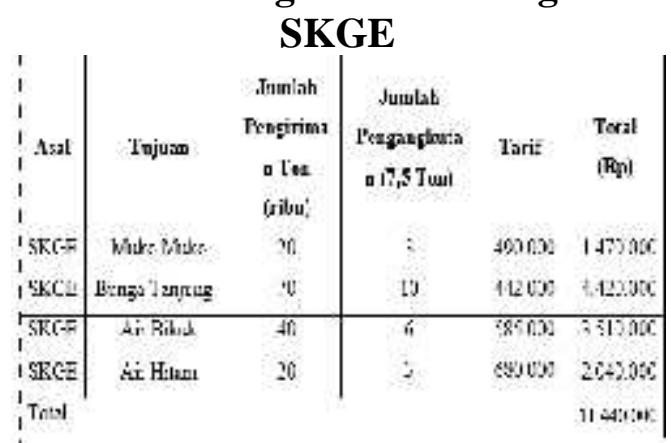

Dari data yang didapatkan dari PT. Agro Muko bahwa selama proses pengangkutan dalam pengiriman hanya dapat dilakukan dengan beban maksimal sebesar 7,5 ton/sekali kirim. Jadi dapat dijelaskan dari data tabel 4.2 dari asal gudang SKGE dengan tujuan pengiriman Bunga Tanjung terdapat pengiriman sebanyak 10 (Sepuluh) kali pengiriman. 9 pengiriman dengan kapasitas 7,5 ton dan 1 pengiriman dengan kapasitas 2,5 ton.
3. Berikut ini adalah Tabel pengiriman Buah kelapa sawit dari TRE (Tanah Rekah Estate) Yang akan dikirim ke beberapa pabrik, Di mana Masing - masing Tempat mempunyai Tarif yang Berbeda, yang ditetukan oleh PT. Agro Muko . Dari TRE (Tanah Rekah Estate) ke;

a. Pabrik Muko Muko, $\quad$ : $\quad R p$ 357.000

b. Pabrik Bunga Tanjung, : Rp 309.000

c. Pabrik Air Bikuk, :Rp 452.000

d. Pabrik Air Hitam, : Rp 547.000

Tabel 4.3 Pengiriman Barang dari

\begin{tabular}{|c|c|c|c|c|c|}
\hline tal & Tujors & 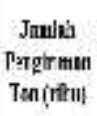 & 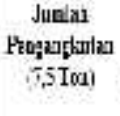 & $\begin{array}{c}\text { luit } \\
\text { Peupjinm }\end{array}$ & Tral \\
\hline IK & Mibulile: & DII & 3 & Ruj5700 & $\mathrm{kg}[\mathrm{f} / \mathrm{g}] \mathrm{b}$ \\
\hline TRE & Buxse Tusug & 30 & 1 & $R_{2} r a m s$ & Rot 13502 \\
\hline IKE & Air silus & iv & IC & $R 442000$ & 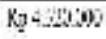 \\
\hline TR: & Ar Finm & fil & II & 8275092 & Bpant7om \\
\hline \multicolumn{5}{|l|}{ Tyel } & 691:34;92 \\
\hline
\end{tabular}

Dari data yang didapatkan dari PT.Agro Muko bahwa selama proses pengangkutan dalam pengiriman hanya dapat dilakukan dengan beban maksimal sebesar 7,5 ton/sekali kirim. Jadi dapat dijelaskan dari data tabel 4.3 dari asal gudang TRE dengan tujuan pengiriman Air Hitam terdapat pengiriman sebanyak 11 (Sebelas) kali pengiriman. 10 pengiriman dengan kapasitas masing-masing 7,5 ton dan 1 pengiriman dengan kapasitas 5 ton.

Total biaya pengiriman $=$ TRE + SKGE + TRE

$$
\begin{aligned}
& =\quad \operatorname{Rp} 26.618 .000+\mathrm{Rp} \\
& 11.440 .000+\mathrm{Rp} 12.844 .000 \\
& =\mathbf{R p 5 0 . 9 0 2 . 0 0 0}
\end{aligned}
$$

Langkah 1 :

Dalam menyelesaikan masalah penghematan biaya pengiriman dengan menggunakan metode north west corner yaitu membuat tabel north west corner. Berikut ini merupakan tabel North West Corner 
langkah pertama yang dapat dilihat pada tabel 4.4.

Tabel 4.4 Tabel North West CornerLangkah Pertama

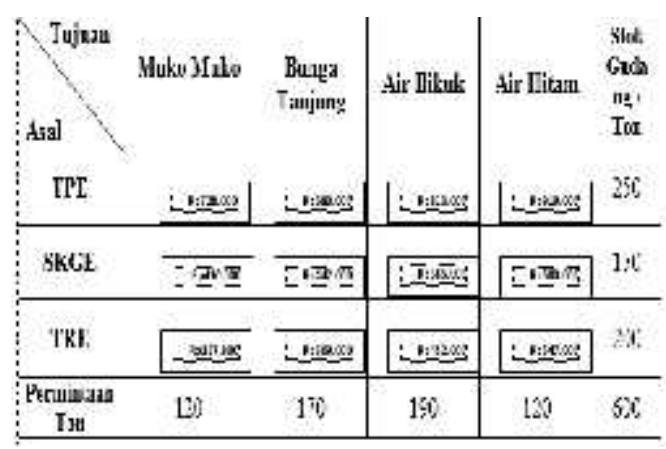

Data stok gudang/ton didapatkan dari hasil pengumpulan data pada PT. Agro Muko. Pada asal TPE stok 250 ton, asal SKGE stok 150 ton dan asal TRE stok 200 ton. Sedangkan data permintaan/ton telah diuraikan dari data pada tabel 4.1, tabel 4.2 dan tabel 4.3 yang setiap tujuan telah dilakukan akumulasi berdasarkan tujuan yang akan dikirim. Pada tujuan Muko-Muko di tabel 4.1 beban pengiriman sebsar 80 ton, pada tabel 4.2 dengan tujuan yang sama yaitu Muko-Muko beban pengiriman sebesar 20 ton, dan pada tabel 4.3 beban pengiriman sebesar 20 ton, dapat diakumulasikan khusus untuk tujuan Muko-Muko beban angkut sebesar 120 ton. Dari uraian data tersebut dapat dihasilkan beban angkut untuk tujuan Bunga Tanjung sebesar 170 ton, Air Bikuk 190 ton dan Air Hitam 120 ton.

Langkah 2 :

Mulai dari sudut kiri atas dialokasikan sejumlah maksimum dengan melihat kapasitas stok gudang dan permintaan yaitu sebesar 120 ton. Berikut merupakan tabel North West Corner langkah kedua yang dapat dilihat pada tabel 4.5

\section{Tabel 4.5 Tabel North West CornerLangkah kedua}

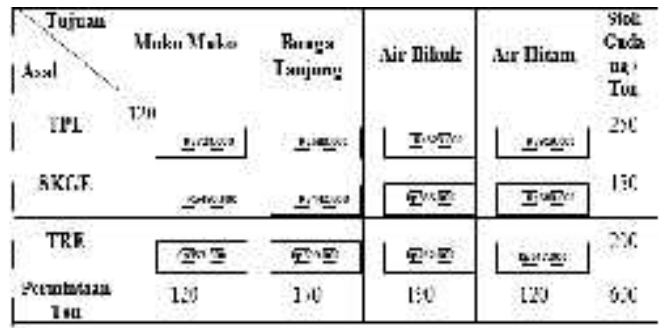

Langkah 3 :

Semua permintaan di Pabrik Muko Muko telah terpenuhi dan masih ada sisa stok 130 ton lagi di Gudang TPE. Kemudian lanjutkan ke Pabrik di Bunga Tanjung, isi sesuai dengan permintaan dan stok di gudang.

Tabel 4.6 Tabel North West CornerLangkah Ketiga

\begin{tabular}{|c|c|c|c|c|c|}
\hline Tujwan & to Mrako & $\begin{array}{l}\text { Bunga } \\
\text { Tuijung }\end{array}$ & Air Eikuk & Air Hitan & $\begin{array}{l}\text { Erot } \\
\text { fiuts: } \\
\text { g: } \\
\text { Tou }\end{array}$ \\
\hline TPF & $-\underline{2 x: 1 \alpha}$ & 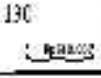 & $-B$ & siancus & 256 \\
\hline SEGI & Exesp & $\vdots \overline{\underline{B}} 20 \overline{\underline{Z}}$ & 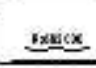 & bitances & $t 5$ \\
\hline TRF. & 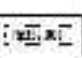 & 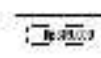 & . & atras: & $3 x$ \\
\hline $\begin{array}{c}\text { Pernuatsas } \\
\text { Tos }\end{array}$ & (3) & $10^{\circ}$ & wy & in & $c^{2} 0$ \\
\hline
\end{tabular}

\section{Langkah 4 :}

Permintaan di pabrik Bunga Tanjung belum terpenuhi yaitu sebesar 40 ton, maka akan dipenuhi dari SKGE. Di mana jumlah stok dari SKGE sebanyak 150 ton, dan kelebihan stok dari SKGE akan didistribusikan ke Air Bikuk sebesar 110 ton.

Tabel 4.7 Tabel North West Corner Langkah Keempat 


\begin{tabular}{|c|c|c|c|c|c|}
\hline $\begin{array}{l}\text { Iuikan } \\
1 \\
1 \\
\text { i.tsial }\end{array}$ & Mnkn Vate & $\begin{array}{l}\text { Rurgas } \\
\text { Tinjumg }\end{array}$ & Air Bikuk & Sir Eilam & $\begin{array}{l}\text { Sink } \\
\text { Enix } \\
\text { min } \\
\text { Tm }\end{array}$ \\
\hline TrT & ${ }^{120}$ & 130 & 1 I & 1 I. & 270 \\
\hline SKGE & 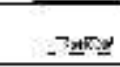 & 45 & Liaa․ & 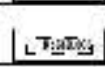 & 150 \\
\hline : TRE & 2 메느- & 누느믄 & 누프므. & 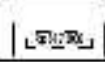 & 30 \\
\hline 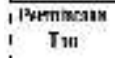 & $m$ & 170 & $13 \%$ & 120 & Sin \\
\hline
\end{tabular}

4. Hal lain akan menghabiskan salah satu dari sumber stok barang ke tujuan stok pertama, sehingga tidak ada lagi barang yang dapat dialokasikan ke kolom atau baris.

Tabel 4.8 Tabel North West Corner Langkah Kelima

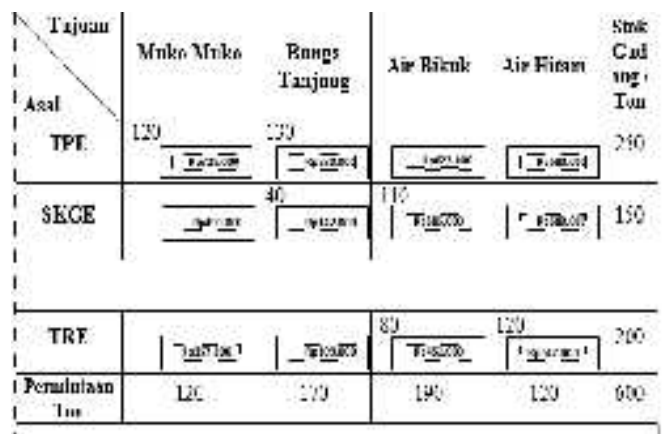

5.Alokasikan sebanyak mungkin ke kotak didekatnya pada baris dan kolom yang belum terisi. Apabila kolom maupun baris telah terpenuhi, maka pindah secara diagonal ke kotak berikutnya.

6. Lanjutkan dengan cara yang sama sehingga semua stok barang telah habis dan permintaan telah terpenuhi.

7.Lanjutkan dengan menghitung biaya transportasi. Hasil perhitungan adalah hasil yang didapat dengan metode North West Corner.

Langkah 6 :

Lanjutkan dengan menghitung biaya pengiriman barang yang ada pada tabel North West Corner. Ingat bahwa kapasitas pengiriman hanya 7,5 ton, Apabila melebihi dari 7,5 ton, maka tarif Pengiriman harus dikali kelipatan.

Biaya angkut dari TPE:
TPE - Muko Muko $=120$ Ton $=(16 \mathrm{x}$ Rp 728.000)

$=\operatorname{Rp} 11.648 .000$

TPE - Bunga Tanjung $=130$ Ton $=(18$ x Rp 680.000)

$=\mathrm{Rp} 12.240 .000$

Maka total biaya angkut dari TPE $=$

Rp 11.648.000 + Rp 12.240.000

$=\operatorname{Rp} 23.888 .000$

Biaya angkut dari SKGE :

SKGE - Bunga Tanjung $=40$ Ton $=(6$

$x \operatorname{Rp} 442.000$ )

$=\operatorname{Rp} 2.652 .000$

SKGE - Air Bikuk $=110$ Ton $=(15 \mathrm{x}$

Rp 585.000)

$=\operatorname{Rp} 8.775 .000$

Maka total biaya angkut dari SKGE=

Rp 2.652.000 + Rp 8.775.000

$=\operatorname{Rp} 11.427 .000$

Biaya angkut dari TRE :

TRE - Air Bikuk $=80$ Ton $=(11 \times$ Rp 452.000 )

$=\mathrm{Rp} 4.972 .000$

TRE - Air Hitam $=120$ Ton $=(16 \mathrm{x}$

Rp 547.000 )

$=\operatorname{Rp} 8.752 .000$

Maka total biaya angkut dari TRE=

Rp 4.972.000 + Rp 8.752.000

$=\operatorname{Rp} 13.724 .000$

Total biaya transportasi $=$ TPE +

SKGE + SKGE

$=\mathrm{Rp} 23.888 .000+\mathrm{Rp} \mathrm{11.427.000+}$

Rp 13.724.000

$=\mathbf{R p}$ 49.039.0000

Jadi dengan menggunakan metode North West Corner, dapat menghemat biaya transportasi sebesar

$=\mathbf{R p}$ 50.902.000 $-\mathbf{R p}$ 49.039.000

$=R \mathbf{p} 1.863 .000$

\section{SIMPULAN}

Penerapan metode North West Corner untuk penghematan biaya transportasi pada PT.Agro Muko telah diselesaikan, sehingga dapat diambil beberapa kesimpulan di antaranya adalah sebagai berikut :

1. Hasil yang diperoleh dari metode north west corner dalam optimalisasi biaya pengiriman 
transportasi pada PT.Agro Muko menghasilkan selisih biaya dengan rata-rata $3,66 \%$.

2. Dari hasil metode north west corner dapat memudahkan manajemen PT.Agro Muko untuk menentukan solusi awal dan menentukan pengalokasian dari transportasi.

\section{DAFTAR PUSTAKA}

Agus Sasmito Ariwibowo (2008), Visualisasi teori Optimalisasi Biaya Transportasi Untuk Pembelajaran Riset Operasi, Seminar Nasional Informatika ( Semnas IF 2008) UPN.

Taghrid Imam Gaber Elsharawy Mohamed Gomah Iman Samy, Pemecahan masalah Transportasi Menggunakan Object-Oriented Model. IJCSNS International Journal of Ilmu Komputer dan Keamanan Jaringan, vol.9 No.2, Februari 2009

Claudia Nelwan, John S. Kekenusa, Yohanes Langi, Optimasi Pendistribusian Air Dengan Menggunakan Metode Last Cost Dan Metode Modified Distribution (Studi kasus : PDAM Kabupaten Minahasa Utara) Jurnal ilmiah Sains Vol.13 No.1 April 2013

Lim Sanny, Total biaya Ditribusi Minimum dengan pendekatan Metode Transportasi, Jurnal Manajemen dan Ekonomi Pembangunan. Volume 9, Nomor 2, Desember 2011, ISSN 14102293

Hendri. J (2009), Riset Operasional , Universitas Gunadarma Volume 9 No.2, 2012, ISSN : 1203-1900.

Irwan Syahputra, Perancangan Aplikasi Sistem Puri terima Barang Menerapkan North West Corner Method (NWC) Pada PT.Pos
Indonesia Medan. Informasi dan Teknologi Ilmiah (INTI) Volume : V, Nomor : 2, Januari 2015 ISSN : 2339210X

J.I. Maanari, R.Sengkey,ST.,MT.,Ir. H. Wowor, M.kom, Perancangan Basis Data Perusahaan Distribusi dengan Menggunakan Oracle. Jurusan Teknik Elektro-FT, UNSRAT, Manado-95115 : e-journal Teknik Elektro dan Komputer (2013) 